Published in: Thermochimica Acta 602 (2015) 63-73; http://dx.doi.org/10.1016/j.tca.2014.12.023

\title{
Quench-induced precipitates in Al-Si alloys: Calorimetric determination of solute content and characterisation of microstructure
}

\author{
Philipp Schumacher, ${ }^{\mathrm{a}, \mathrm{b}}$, Stefan Pogatscher ${ }^{\mathrm{c}}$, Marco J Starink ${ }^{\mathrm{d}}$, Christoph Schick ${ }^{\mathrm{b}}$, \\ Volker Mohles ${ }^{\mathrm{e}}$ and Benjamin Milkereit ${ }^{\mathrm{a}, \mathrm{b}, \mathrm{d}, *}$
}

${ }^{\text {a } U n i v e r s i t y ~ o f ~ R o s t o c k ~}$

Faculty of Mechanical Engineering and Marine Technology

Chair of Materials Science

Albert-Einstein-Str. 2, 18051 Rostock, Germany

10 (philipp.schumacher@uni-rostock.de, benjamin.milkereit@uni-rostock.de)

${ }^{\mathrm{b}}$ University of Rostock

Institute of Physics

Polymer Physics Group

Wismarsche Str. 43-45,18051 Rostock, Germany

(christoph.schick@uni-rostock.de)

\section{${ }^{c}$ ETH Zurich}

Department of Materials

20 Laboratory of Metal Physics and Technology

Vladimir-Prelog-Weg 4, 8093 Zurich, Switzerland

(stefan.pogatscher@mat.ethz.ch)

${ }^{\mathrm{d}}$ University of Southampton

Engineering and the Environment

Highfield, Southampton SO17 1BJ, United Kingdom

(m.j.starink@soton.ac.uk)

e RWTH Aachen University

30 Institute of Physical Metallurgy and Metal Physics

Kopernikusstr. 14, 52056 Aachen, Germany

(mohles@imm.rwth-aachen.de)

* Corresponding author:

Benjamin Milkereit

University of Rostock

Faculty of Mechanical Engineering and Marine Technology

Chair of Materials Science

Albert Einstein-Str. 2, 18051 Rostock, Germany

40 E-mail address: benjamin.milkereit@ uni-rostock.de

Tel.: +49 (0) 3814989486 


\begin{abstract}
The present study introduces an experimental approach to investigate mechanical properties of well-defined nonequilibrium states of Al-Si alloys during cooling from solution annealing. The precipitation behaviour of binary Al-Si alloys during the cooling process has been investigated in a wide cooling rate range $(2 \mathrm{~K} / \mathrm{s}-0.0001 \mathrm{~K} / \mathrm{s})$ with differential scanning calorimetry (DSC). To access the low cooling rate range close to equilibrium an indirect DSC measurement method is introduced. Based on the enthalpy change measured by DSC a physically-based model for the calculation of remaining solute $\mathrm{Si}$ amount as function of temperature and cooling rate is presented.

50 Microstructural analyses via light optical microscopy, scanning electron microscopy, atom probe tomography and X-ray diffraction have been performed to evaluate the introduced model and for information on cooling rate dependent precipitate formation. It was found that quench-induced particles of different morphology are formed during cooling. Thermomechanical analyses on clearly distinct undercooled Al-Si states show that flow stress during cooling is dependent on temperature as well as cooling rate. The mechanical behaviour is therefore influenced by solute Si content and quench-induced precipitates.
\end{abstract}

\title{
Keywords
}

Al-Si alloys, DSC, Precipitation enthalpy, Modelling, Microstructure control, Mechanical properties testing

\section{Introduction}

Age hardening is an important heat treatment to strengthen heat treatable aluminium alloys and comprises three 60 steps - solution annealing, quenching and ageing [1]. The quenching rate is an important parameter within this treatment. If solution temperature and cooling conditions are chosen correctly, all solute elements from which strengthening particles can be precipitated during subsequent ageing are retained in the supersaturated solution. Slower cooling on the other hand may induce precipitation of coarse second-phase particles. A lower amount of solute will thus be available for precipitation of the hardening phases, resulting in a lower strength after peak ageing. Excessive cooling rates should also be avoided as they cause high thermal gradients in the treated components, which might induce residual stresses and distortion. The quenching process can therefore be considered as a critical step of the age hardening process.

Prediction of the effect of cooling conditions on residual stresses and distortion can be established by numerical heat treatment simulations using finite element methods (FEM, e.g. [2]). However, such simulations require 70 profound knowledge about the materials' flow characteristics in dependence on temperatures, strain rates and microstructures. While empirical flow stress relations that are often implemented in FEM codes give remarkably good description of measured flow curves of defined material conditions, they are in many cases unsuitable to describe the mechanical behaviour under process-like conditions. In particular, flow behaviour is to a great extent influenced by the cooling rate as microstructural changes, including microchemical composition of the matrix 
and precipitation state, can occur during the cooling step. Hence, the usual description of flow stress with macroscopic state variables (strain and overall chemical composition) is unsatisfactory in certain cases [3]. Approaches to model flow curves with more appropriate state variables have therefore been developed in the past (e.g. [4-6]). While stress-strain curves of pure aluminium and alloys with very low solute content can already be predicted over a wide range of temperatures and strain rates [7,8], influences of additional microstructural 80 elements such as solutes and second-phase particles need further investigation.

It is known that flow stress of commercial age-hardenable aluminium alloys increase not only with decreasing temperature but also with increasing cooling rate, and in some works solid solution strengthening was considered to be responsible for this material behaviour (e.g. [9]). Hence, the precipitation behaviour during cooling is of great importance as it provides knowledge on the loss of solutes and on microstructural changes. The effect of single elements on solute strengthening in aluminium alloys was experimentally studied in several works (e.g. [10-14]). However, contribution on solid solution strengthening during the cooling process has not been subject to investigations so far. Furthermore, the role of quench-induced precipitates on the mechanical behaviour remains uncertain.

We aim to improve existing plasticity models with respect to microstructure evolution during quenching in the 90 future. Therefore, reliable experimental data of well-defined material states is needed to investigate active strengthening mechanisms, which have to be modelled. While strength of commercial alloys originates from a combined effect of several factors such as solid solution, grain size, aging precipitates, dispersoids or primary particles, binary alloys of high purity allow the isolation of several strength contributions [10]. Thus, binary alloys of the Al-Si system are analysed in a first step here. Al-Si is an ideal model system for the investigation of precipitation kinetics, since exothermic reactions are always due to precipitation of $\mathrm{Si}$ [15] and solubility of $\mathrm{Al}$ in the Si phase is low [16,17]. Furthermore, knowledge on influence of single alloying elements on mechanical properties is considered to be important in order to set up a new plasticity model for commercial aluminium alloys.

The present paper introduces an approach to produce well-defined microstructural states that allow a detailed 100 study of the effect of Si solutes and quench-induced Si precipitates on mechanical properties. To control the microstructure, i.e. the microchemical composition of the matrix and the corresponding precipitation state, differential scanning calorimetry (DSC) measurements are of great importance. It was shown in $[18,19]$ that the precipitation heat (enthalpy change) is directly proportional to the volume fraction of precipitated particles, which allows in principle a calculation of remaining solute amount in dependence of cooling rate and temperature [20]. One main objective of the present work is a precise determination of formation enthalpies to provide detailed input for a physically-based model. Therefore, precipitation kinetics of low-Si binary Al-Si alloys during cooling from solution annealing are investigated in a wide cooling rate range with advanced DSC techniques (e.g. [18,2128]). Direct DSC cooling experiments are limited to a certain slow cooling rate due to the relation between sample mass, cooling rate and heat flow. At a certain rate the signal-to-noise ratio of any DSC device will become too 
110 small to allow signal evaluation. However, the knowledge of near equilibrium precipitation processes is the basis for the setup of any model. To access the cooling rate range close to equilibrium conditions a new indirect DSC reheating technique is introduced, which allows the quantitative evaluation of the precipitation enthalpy. Based on the enthalpy change measured by DSC, a model for the calculation of remaining solute $\mathrm{Si}$ amount and precipitation volume fraction as functions of temperature and cooling rate is presented, adapting an improved model for diffusion controlled reactions [29]. The microstructures of the defined states are analysed to evaluate the introduced model. Thereby, remaining solute amount and quench-induced precipitates are characterised with various methods: light optical and scanning electron microscopy (LOM / SEM), X-ray diffraction (XRD) and atom probe tomography (APT).

The mechanical behaviour of non-equilibrium microstructures is investigated by thermomechanical 120 analysis (TMA) using a quenching and deformation dilatometer [9]. It is shown that the experimental methods can be applied for a systematic study on the correlation between microstructural states of undercooled aluminium alloys and their mechanical behaviour. With the presented experimental approach the effect of Si solutes and quench-induced $\mathrm{Si}$ precipitates on mechanical properties can be analysed in future, which is an essential requirement for the progression of plasticity models.

\section{Experimental}

\subsection{Materials}

Two binary Al-Si alloys of high-purity grades were studied in this work. Their chemical compositions obtained by optical emission spectroscopy (OES) analyses are shown in Table 1.

Table 1. Chemical compositions of investigated alloys obtained by optical emission spectroscopy (OES) analysis.

\begin{tabular}{c|cccccccc}
$\begin{array}{c}\text { mass } \\
\text { fractions }\end{array}$ & $\begin{array}{c}\mathrm{Si} \\
(\mathrm{ma} . \% / \mathrm{at} \%)\end{array}$ & $\begin{array}{c}\mathrm{Mg} \\
(\mathrm{ppm})\end{array}$ & $\begin{array}{c}\mathrm{Fe} \\
(\mathrm{ppm})\end{array}$ & $\begin{array}{c}\mathrm{Cu} \\
(\mathrm{ppm})\end{array}$ & $\begin{array}{c}\mathrm{Mn} \\
(\mathrm{ppm})\end{array}$ & $\begin{array}{c}\mathrm{Cr} \\
(\mathrm{ppm})\end{array}$ & $\begin{array}{c}\mathrm{Zn} \\
(\mathrm{ppm})\end{array}$ & $\begin{array}{c}\mathrm{Ti} \\
(\mathrm{ppm})\end{array}$ \\
\hline $\mathrm{Al}-0.26 \mathrm{Si}$ & $0.26 / 0.25$ & $<1$ & $<5$ & 4 & $<3$ & $<3$ & - & 20 \\
$\mathrm{Al}-0.72 \mathrm{Si}$ & $0.72 / 0.69$ & $<1$ & $<5$ & $<1$ & $<3$ & $<3$ & 14 & 11
\end{tabular}

130 Direct chill (DC) cast ingots were made from aluminium of $99.999 \%$ purity and high-purity alloying elements. The DC cast ingots were homogenised $\left(12\right.$ hours at $\left.500{ }^{\circ} \mathrm{C}\right)$ to obtain a uniform distribution of alloying element atoms and were subsequently hot-rolled to strips of $40 \mathrm{~mm}$ thickness. The hot-rolled strips were solution annealed for 24 hours at $450{ }^{\circ} \mathrm{C}$ followed by water quenching. Finally, the strips were cold-rolled to sheets of $16 \mathrm{~mm}$ thickness. Sampling for all experimental investigations was carried out perpendicular to the rolling direction. In the as-rolled condition both alloys had a similar grain structure with coarse, elongated grains of high aspect ratios. All subsequent investigations included a solution treatment, which resulted in a recrystallized structure with grain sizes of about $450 \mu \mathrm{m}$ in both alloys. 


\subsection{Methods}

A very wide range of cooling rates must be examined in order to fully understand the precipitation behaviour 140 during cooling from solution annealing $[18,22,24,26]$. Three different types of DSC devices were used: PerkinElmer Pyris Diamond DSC ( 2 to $0.3 \mathrm{~K} / \mathrm{s}$ ), Setaram $121 \mathrm{DSC}(0.1$ to $0.01 \mathrm{~K} / \mathrm{s}$ ) and Setaram C600 DSC (0.005 to $0.001 \mathrm{~K} / \mathrm{s})$. The methods employed for direct DSC cooling experiments and evaluation for the fastest and intermediate cooling rate ranges are described in [22]. While six measurements with identical parameters were performed in the Pyris Diamond DSC and at least three runs under same conditions were executed in the Setaram 121 DSC, only one or two experiments for each cooling rate were carried out in the C600 DSC due to the extensive test durations. High purity aluminium (99.9995\%) was taken as reference and data evaluation was done on excess specific heat capacity curves [22]. In-situ solution annealing was performed at $540{ }^{\circ} \mathrm{C}$ for 20 min except for measurements in the C600 DSC device, which required $120 \mathrm{~min}$ to reach thermal equilibrium within the measuring system due to the relatively large heat capacity of sample and measuring block. A well-stabilised 150 temperature of the system at solution annealing is needed for high quality specific heat capacity measurements. Note that the different solution treatment times did not result in different grain sizes.

The study of slow cooling rates provides the opportunity to follow near equilibrium phase changes. This is an essential requirement for a physical approach to describe the solute state during cooling. With reference to previous work (e.g. $[18,22,28]$ ), the accessible cooling rate could be extended to very low values using the Setaram C600 DSC device with the following certain boundary conditions. Thus, cooling rates comprising four orders of magnitude could be analysed by direct cooling experiments. The Setaram C600 calorimeter is a heat flux DSC with a cylinder-type measuring system and is equipped with a high precision 3D Calvet sensor, which totally surrounds sample and reference cell. This setup provides that nearly all heat evolved is measured. Measurements comprising a temperature range from ambient temperature up to $600{ }^{\circ} \mathrm{C}$ can be realised. A closed 160 cooling circuit was implemented using a refrigerated circulator Julabo F34-ED. Optimal results were achieved by using cylindrical samples with radiused edges. The samples had dimensions of $13.8 \mathrm{~mm}$ in diameter and $60.5 \mathrm{~mm}$ in length, which results in a sample mass of approximately $24,000 \mathrm{mg}$. The samples as well as the references were covered by conventional aluminium foil (about $110 \mathrm{mg}$ ) to minimize radiation losses caused by surface reactions of the samples.

A detailed analyses of alloys with very slow precipitation kinetics is hard to achieve with direct DSC cooling experiments, because an adequate statistical basis is very difficult to achieve due to extensive test durations. In order to determine the saturation value of enthalpy change for near equilibrium phase changes in such alloys, an expansion of cooling rate range to even lower rates than $0.001 \mathrm{~K} / \mathrm{s}$ is necessary. This aim can hardly be established by any direct DSC cooling experiments with state of the art devices due to a low signal-to-noise ratio. Therefore, 170 another approach based on the differential reheating method [24] was undertaken to deal with the mentioned difficulties. With implementation of the reheating method information on enthalpy changes caused by precipitation during cooling can be derived from DSC reheating experiments. Even though DSC heating curves 
of aluminium alloys are often difficult to interpret in terms of quality, quantitative information can easily be obtained, provided the baseline is determined accurately. The reheating method takes as a basis that the total enthalpy change in a closed thermodynamic cycle equals zero under the premise that starting and end point are in equilibrium. The schematic temperature-time profile, indicating the enthalpy changes for the reheating method is shown in Fig. 1. For the given problem the complete solid solution at the end of the solution annealing process can be defined as such an equilibrium state with a precipitation enthalpy value of $H_{0}=0$. During slow cooling from solution annealing exothermic precipitation reactions take place causing a negative enthalpy change $\Delta H_{\text {SC }}$.

180 Provided that the same equilibrium state $H_{0}$ as before is achieved after a reheating cycle following the cooling process, the sum of enthalpy changes of the cooling step $\Delta H_{\mathrm{SC}}$ and the reheating step $\Delta H_{\mathrm{RH}}$ must be zero $\left(\Delta H_{\mathrm{SC}}+\Delta H_{\mathrm{RH}}=0\right)$.

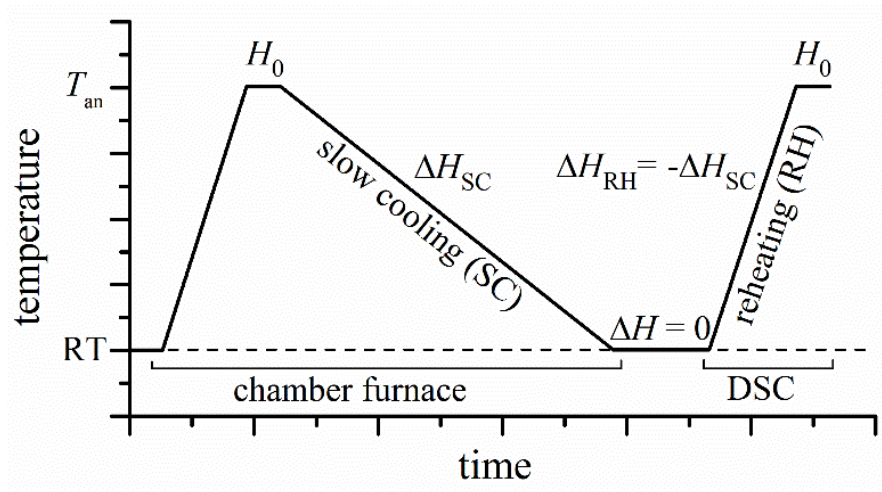

Fig. 1. Temperature-time profile for indirect determination of specific precipitation heat values during cooling with very slow rates by a DSC reheating scan.

For a sample cooled with a specific rate, a defined sequence of exothermic and endothermic reactions is detectable during the reheating cycle. Equilibrium state is achieved when all reactions are completed before the annealing temperature $T_{\mathrm{an}}$ is reached, i.e. the temperature exceeds the solvus temperature of the applied scanning rate. If this is the case all precipitated particles which have been formed during previous cooling and during the reheating 190 step, respectively, are resolved and a complete solid solution with an enthalpy value $H_{0}$ is restored. On condition that equilibrium state is achieved after reheating, $\Delta H_{\mathrm{SC}}$ can be calculated directly from the DSC curves of the heating step. For an optimal control and evaluation of the corresponding baseline, it is recommended that sample temperature exceeds the corresponding solvus temperature for some $10 \mathrm{~K}$. In that case, baseline bending correction can be performed [22]. The essential benefit of this reheating method is the possibility to study characteristic physical properties for cooling rates unattainable with direct DSC measurements. Another significant advantage is the reduced duration of experiments directly performed in DSC devices because the first thermal cycle comprising the cooling process can be executed simultaneously on various samples in an appropriate furnace. In this work, solution annealing $\left(540{ }^{\circ} \mathrm{C}, 20 \mathrm{~min}\right)$ and slow cooling with nearly constant rate was realised in a chamber furnace Carbolite CWF 11/13 equipped with an Invensys Eurotherm nanodac ${ }^{\mathrm{TM}}$ 200 recorder/controller for cascade control. Prior to heat treatment samples were sealed in quartz glass under vacuum 
in order to prevent surface reactions and thus changes in chemical composition. In addition to near equilibrium slow cooling rates, the as quenched condition after cooling in water was analysed as a reference and control measurement. After the cooling process samples were stored at $-82{ }^{\circ} \mathrm{C}$ to supress further potential precipitation reactions before they were reheated in the Setaram C600 DSC to a temperature of $570{ }^{\circ} \mathrm{C}$. A heating rate of $0.003 \mathrm{~K} / \mathrm{s}$ was chosen for those experiments as this is an optimal rate for this DSC device and also ensures the observance of the mentioned requirement for this method that is the achievement of a complete solid solution before the end of the heating step (this applies to all cooling rates down to $0.0001 \mathrm{~K} / \mathrm{s}$ investigated here). At least two experiments were carried out for each material condition.

With knowledge of precipitate formation enthalpies derived from DSC measurements a model for the calculation 210 of the solute Si content as a function of cooling rate and temperature was developed (presented in section 3.3). For evaluation of this model and for the characterisation of quench-induced precipitates, metallographic investigations were carried out. Selected cooling states were investigated by LOM with a Leica DMI5000 M and SEM performed in a Zeiss Supra 25 microscope operated at $10 \mathrm{kV}$. Samples were prepared by standard grinding and polishing methods with water-free, ethanol-based lubricants. For the final polishing step an oxide polishing suspension was used. From microscopic images the volume fraction of precipitated particles was determined with stereological methods using computational image analysis [30]. For each investigated cooling condition, fifty images (analysed area per condition $>9.5 \times 10^{6} \mu \mathrm{m}^{2}$ ) were evaluated to ensure statistical validation. It is well established in literature that only the diamond cubic Si-rich phase $(\mathrm{a}=0.542 \mathrm{~nm})$ is precipitated from Al-Si supersaturated solid solution (e.g. [1]). As only coarse particles of equilibrium phase seem to form during cooling 220 the amount of remaining solute can be calculated from metallographic results and taken for comparison with the solute content derived from DSC data. For direct determination of solute contents, APT measurements were carried out. A standard two-step method [31] was used to prepare needle-shaped specimens $\left(0.3 \times 0.3 \mathrm{~mm}^{2}\right)$. After electropolishing the small rods with $10 \%$ perchloric acid and $90 \%$ methanol solution, $2 \%$ perchloric acid in butoxyethanol was used as the second electrolyte. Prepared needle tips have been checked to only represent the Al-rich matrix and not Si precipitates via SEM. APT was performed on a LEAP ${ }^{\mathrm{TM}} 4000 \mathrm{X}$ HR atom probe at a temperature of $30 \mathrm{~K}$ with a pulse fraction of $20 \%$, a pulse rate of $200 \mathrm{kHz}$ and an evaporation rate of $0.5 \%$ under ultra-high vacuum $\left(<10^{-10} \mathrm{mbar}\right)$. Three successful runs were executed for each analysed condition. For reconstruction procedure and chemical analysis the software package IVAS 3.6.6 ${ }^{\mathrm{TM}}$ from Imago Scientific Instruments Corporation (Madison, WI, USA) was used. Only regions in the analysed volume free from 230 crystallographic pole and zone lines were considered for APT analysis. XRD measurements were performed with a Bruker D8 DISCOVER diffractometer (integral measurements on samples of mm-size) using $\mathrm{Cu}-\mathrm{K} \alpha$ radiation in order to confirm the crystal structures of quench-induced precipitates after cooling with different rates.

The effect of temperature and cooling conditions on flow characteristics of Al-Si was studied by TMA. The experiments were performed in accordance to Ref. [9] using a quenching and deformation dilatometer type Bähr DIL 805 A/D. At least three experiments with identical parameters were performed. True stress and 
logarithmic strain were determined from measured force-displacement curves. Thereby, geometry changes due to thermal expansion were taken into account for tests at elevated temperatures. Samples were solution annealed $\left(540{ }^{\circ} \mathrm{C}, 20 \mathrm{~min}\right)$, cooled with various rates to different temperatures and compressed immediately after reaching the desired temperature. A strain rate of $0.1 \mathrm{~s}^{-1}$ was chosen for these tests. As the precipitation behaviour is 240 investigated dependent on cooling rate and temperature, microstructure of the samples can be taken into account for a discussion of the flow behaviour.

\section{Results and discussion}

\subsection{DSC cooling experiments}

Fig. 2 shows characteristic excess specific heat capacity curves for the investigated Al-Si alloys during cooling after solution annealing. The curves are shifted vertically and arranged in order of increasing cooling rate. DSC devices used for different cooling rate ranges are displayed. Exothermic precipitation reactions are shown by deviations exceeding the zero level, which is given by a dashed line for each curve. Note the various scaling of the excess specific heat capacity axis in Fig. 2a and Fig. 2b. It can be seen that precipitation in the investigated alloys occurs in different cooling rate ranges. Furthermore, peak temperatures and maximum excess specific heat 250 capacities differ significantly between both alloys.

a)

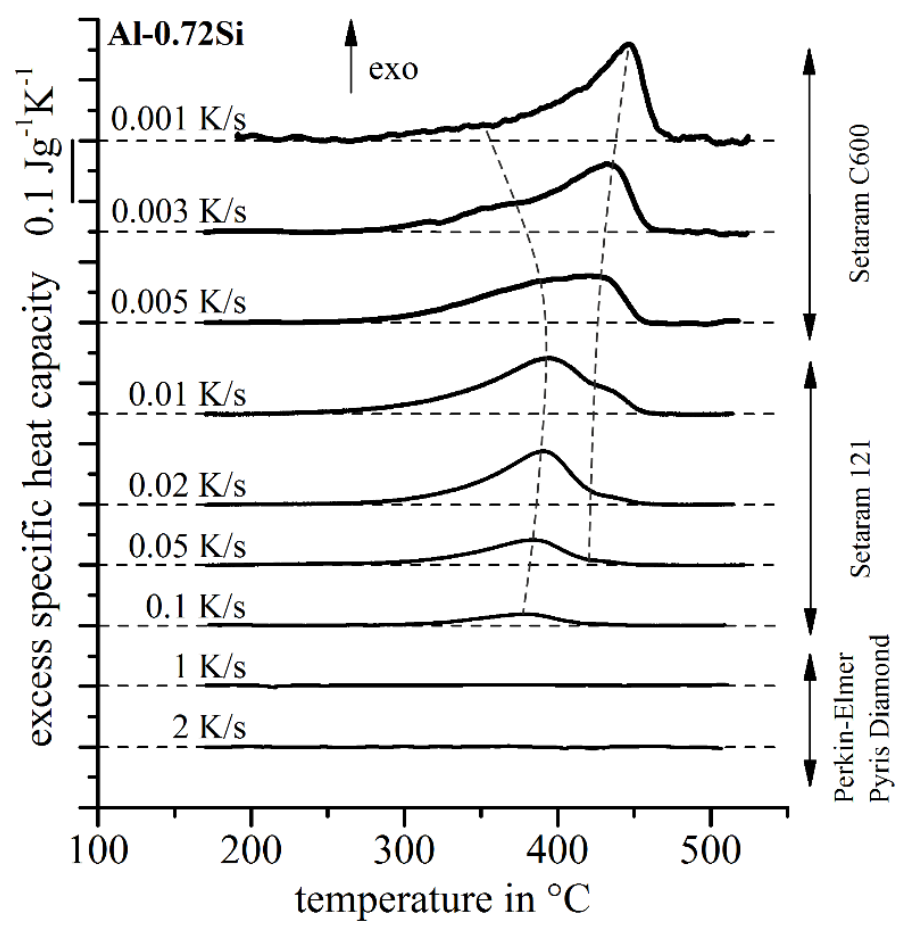

b)

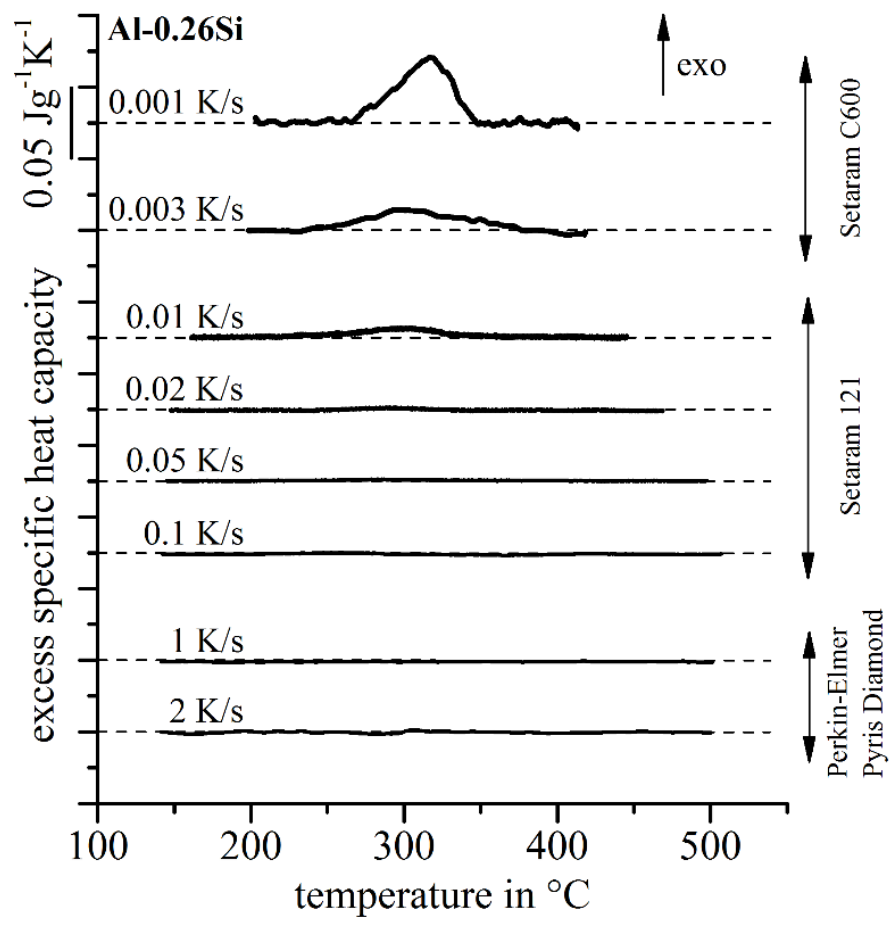

Fig. 2. DSC cooling curves of alloys Al-0.72Si (a) and Al-0.26Si (b) after solution annealing in a cooling rate range from $0.001 \mathrm{~K} / \mathrm{s}$ to $2 \mathrm{~K} / \mathrm{s}$.

For both alloys, precipitation reactions decrease with increasing cooling rate. This can be explained by the suppression of diffusion processes. As only diamond cubic Si-rich phase $(\mathrm{a}=0.542 \mathrm{~nm}$ ) is likely to occur $[1,15]$, 
the occurrence of two reaction peaks for alloy Al-0.72Si within the analysed cooling rate range may seem surprising. For the alloy containing a lower mass fraction of Si only one reaction could be detected in the same cooling rate range. For the slowest investigated cooling rate, precipitation reactions in Al-0.72Si start at about $475{ }^{\circ} \mathrm{C}$, which is very close to the solvus temperature regarding the simple eutectic phase diagram [17] of this 260 binary alloy system. A high temperature precipitation peak is dominating at this cooling condition, but is suppressed significantly in its intensity and shifted towards lower temperatures as the cooling rate increases. While the high temperature reaction is suppressed, another peak at lower temperatures rises to a maximum and shifts to higher temperatures. Such precipitation behaviour is also shown by commercial alloys of different alloying systems (e.g. Al-Mg-Si [18], Al-Zn-Mg(-Cu) [28]).

Further increase in cooling rate results in a decrease of this low temperature peak area as well. Simultaneously, the peak of these low temperature reactions changes its shifting direction and shifts to lower temperatures as observed for commercial alloys before. In [18] "a lower critical cooling rate (LCCR) is defined for the highest cooling rate at which practically complete precipitation takes place. Additionally, an upper critical cooling rate (UCCR) is defined for the slowest cooling rate at which completion of supersaturation in solid solution is reached 270 during cooling." In this work, the UCCR of Al-0.72Si was found to be about $1 \mathrm{~K} / \mathrm{s}$. In Al-0.26Si only one peak was observed even at relatively slow cooling rates. This reaction starts approximately $50 \mathrm{~K}$ below the solvus temperature presented in [17]. As a consequence, it seems probable that precipitation start may be shifted to higher temperatures for even slower cooling. The UCCR of Al-0.26Si was found to be only about $0.02 \mathrm{~K} / \mathrm{s}$.

For Al-0.26Si, reactions even in the faster (with respect to alloy kinetics) cooling rate range could therefore only be detected using relatively slow but high sensitive Calvet-type DSC devices. For cooling rates realisable with a common Perkin-Elmer Pyris Diamond DSC [22] no reactions were measurable. The great potential of Calvettype DSC devices is demonstrated when even slower cooling curves of Al-0.72Si than recorded with the Setaram $121 \mathrm{DSC}$ are investigated. While the cooling curve for $0.01 \mathrm{~K} / \mathrm{s}$ already shows indications that at least two reaction peaks overlap in the temperature range around $400{ }^{\circ} \mathrm{C}$, this precipitation behaviour can only be proven 280 with investigation of slower cooling rates. With the extension of the cooling rate range due to high precision Calvet detectors the existence of a high and a low temperature reaction peak is revealed.

For alloy Al-0.26Si, cooling with a slow rate of $0.01 \mathrm{~K} / \mathrm{s}$ to RT reveals reactions causing an enthalpy change $\left|\Delta H_{\mathrm{RT}}\right|$ of only about $0.58 \mathrm{~J} / \mathrm{g}$. Since the enthalpy characterises the heat content of a system for adiabatic reactions, $\left|\Delta H_{\mathrm{RT}}\right|$ equals the measured specific precipitation heat (integral of excess specific heat capacity). This amount of enthalpy change is close to the detection limit for precipitation reactions of $0.1 \mathrm{~J} / \mathrm{g}$ for the used DSC devices as defined in [22]. Therefore, a further decrease of cooling rate is necessary to distinguish the precipitation peak with certainty from the signals noise level. Only if measurements with the Setaram C600 DSC are taken into account the detected DSC peak can certainly be attributed to precipitation reactions. 


\subsection{DSC reheating experiments}

290 In order to establish the saturation level of enthalpy change for near equilibrium phase changes DSC reheating experiments after cooling with rates down to $0.0001 \mathrm{~K} / \mathrm{s}$ (60 days cooling from solution annealing) were carried out for both alloys. Fig. 3 shows DSC reheating curves of alloy Al-0.72Si in different initial conditions. The precipitation and dissolution sequence during the heating cycle is heavily dependent on the preceded cooling condition.

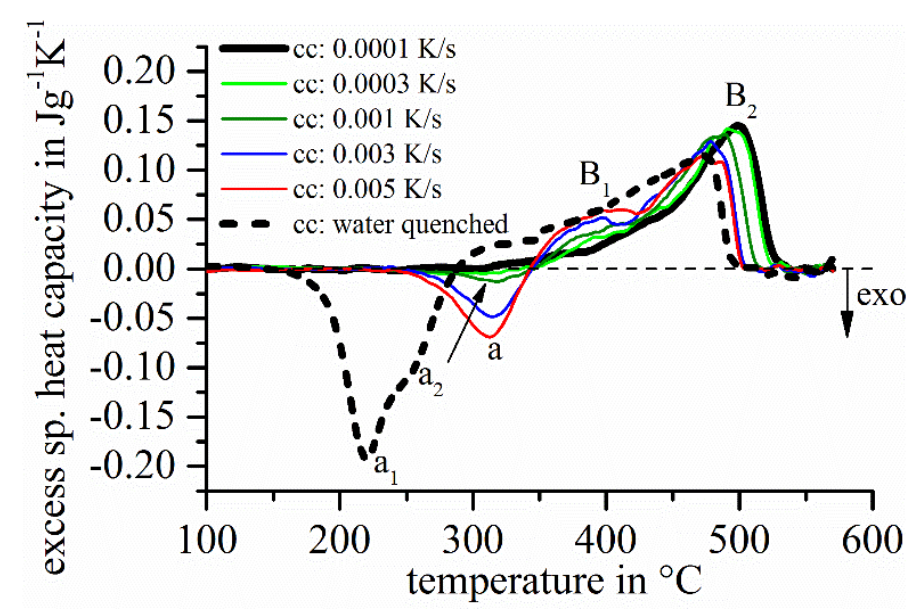

Fig. 3. DSC reheating curves (scan rate: $0.003 \mathrm{~K} / \mathrm{s}$ ) of alloy Al-0.72Si in different cooling conditions (cc).

In general, the sequence shown in Fig. 3 comprises exothermic precipitation reactions and endothermic reactions at higher temperature, which can be attributed to the dissolution of particles. Exothermic precipitation reactions causing two overlapping DSC peaks ( $\mathrm{a}_{1}$ and $\mathrm{a}_{2}$ ) can be observed, when a water quenched sample is reheated. For 300 samples cooled at much lower rates the exothermic peaks are suppressed significantly and also shifted towards higher temperatures. Only one main exothermic peak (a) remains, but one has to be aware of possible peak overlapping which might occur. This main peak shifts to higher temperatures as the preceding cooling rate decreases. The lower the cooling rate in the previous heat treatment was chosen, the more alloying elements are already precipitated during the cooling step. As a consequence, supersaturation of the solid solution is reduced and less Si can be precipitated upon reheating. Hence, the intensity of the exothermic peak (a) decreases with a reduction of cooling rate. Peak (a) disappears when supersaturation after cooling becomes sufficiently small for re-precipitation upon heating. The criterion for the completion of precipitation during cooling should be to maximise the integral of dissolution during heating. In that case all alloying elements insoluble in equilibrium condition at room temperature have been precipitated during previous cooling. In practise this should be quite 310 close to the case when peak (a) disappears completely. Therefore, from the DSC reheating results a LCCR of about $0.0001 \mathrm{~K} / \mathrm{s}$ can be estimated for Al-0.72Si.

Regardless of whether the previous cooling occurred fast or slow endothermic dissolution peaks $\left(\mathrm{B}_{1}\right.$ and $\left.\mathrm{B}_{2}\right)$ are present at higher temperatures. These peaks are shifted to higher temperatures with decreasing cooling rate. This indicates that particles formed at low cooling rates dissolve slower than those precipitated at faster cooling 
conditions. However, the DSC reheating curves show that all dissolution reactions are completed before $570{ }^{\circ} \mathrm{C}$ for all initial conditions and thus a complete solid solution is reached. As a result, the enthalpy change $\Delta H_{\mathrm{SC}}$ evoked by the cooling step can be calculated from the DSC reheating curves.

In Fig. 4 the enthalpy change $\Delta H$ of the different conditions in Fig. 3 during reheating with a scan rate of $0.003 \mathrm{~K} / \mathrm{s}$ is plotted. At high temperatures the equilibrium condition $H_{0}$ is reached and this enthalpy level is defined to be 320 zero. As no precipitation reactions take place during water quenching the enthalpy level should be equal in both initial and reheated condition. When the water quenched condition is reheated the enthalpy evolution indeed starts at the zero level. The precipitation reactions that occur on heating lead to a decrease of enthalpy first. At higher temperatures dissolution of precipitated particles causes endothermic reactions. This results in an increase of enthalpy until the equilibrium level is reached again. Equilibrium level is also achieved after heating of all other initial conditions to $570{ }^{\circ} \mathrm{C}$. However, in these states quench-induced precipitates exist and the initial enthalpy state is therefore negative compared to equilibrium and also differs in dependence of the cooling rate. The initial value of enthalpy change therefore equals $\Delta H_{\mathrm{SC}}$.

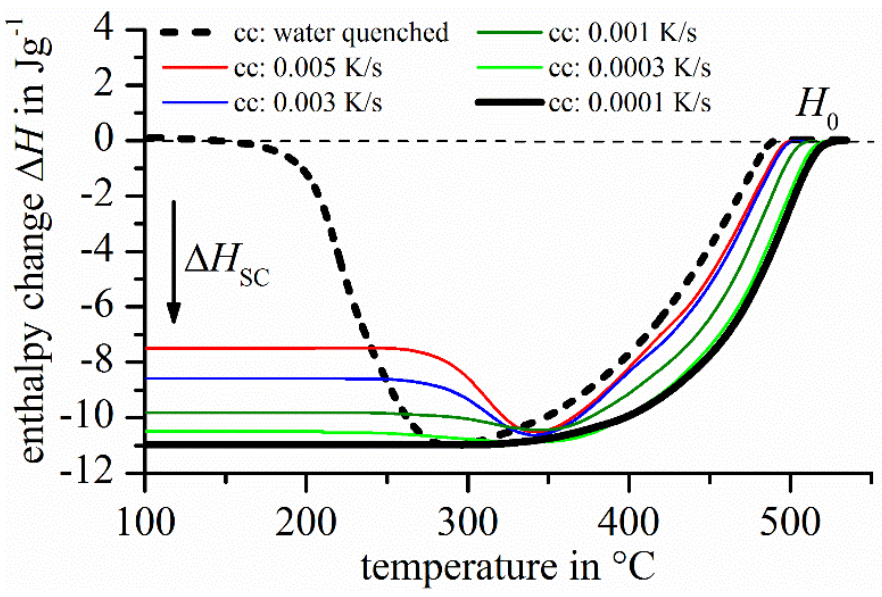

Fig. 4. Change of enthalpy state during reheating (scan rate: $0.003 \mathrm{~K} / \mathrm{s}$ ) of Al-0.72Si in different cooling conditions (cc).

330 Fig. 5 shows the enthalpy change $\left|\Delta H_{\mathrm{RT}}\right|$, after cooling to RT from solution annealing as function of cooling rate. Plotted are both data from direct DSC cooling experiments and values derived with the reheating method for the two investigated alloys. The error of $10 \%$ results from the uncertainty in the determination of the peak-area from DSC data. The data obtained from both methods are in good agreement verifying the feasibility of the reheating method. With DSC reheating experiments the examinable cooling rate range could be extended covering six orders of magnitude between $2 \mathrm{~K} / \mathrm{s}$ and $0.0001 \mathrm{~K} / \mathrm{s}$. 


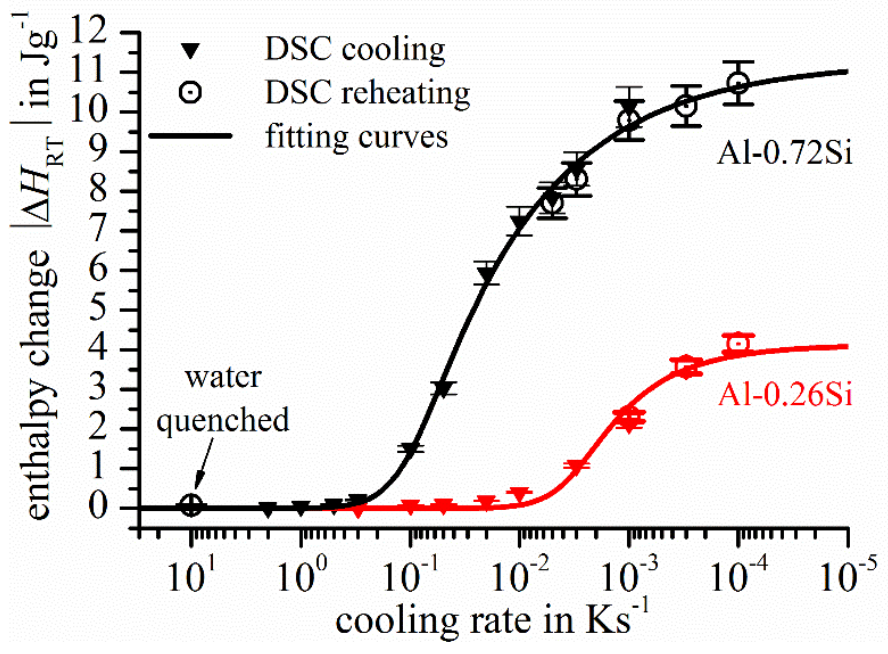

Fig. 5. Enthalpy change values $\left|\Delta H_{\mathrm{RT}}\right|$ upon precipitation in Al-Si alloys after cooling to room temperature obtained with direct DSC cooling experiments or DSC reheating experiments and fitting results with the model presented in Eq. (3).

\subsection{Model for calculation of solute content and precipitated volume fraction}

340 For the control of the microstructure by heat treatment, i.e. the adjustment of well-defined microstructure conditions, a consistent physical description of the volume fraction of precipitates but also of remaining amount of solute in dependence of cooling rate and temperature is needed. To this end we adapt a physically-based model described in [29], which is based on models for diffusion controlled reactions in [32,33]. A prediction of the remaining solute concentration after the quench $C_{\mathrm{AQ}}$ is given as a function of quench factor [29]:

$$
\frac{C_{\mathrm{AQ}}-C_{\min (T)}}{C_{\max (T)}-C_{\min (T)}}=\left[\frac{\left(-k_{1} Q\right)^{n}}{\eta_{i}}+1\right]^{-\eta_{i}}
$$

where $C_{\min (T)}$ is the minimal possible and $C_{\max (T)}$ the maximal possible concentration of solutes at a certain temperature. $Q$ represents the quench factor, while $k_{1}, n$ and $\eta_{i}$ are model parameters. The parameter $n$ is related to the type of nucleation mechanism active $[33,34] . Q$ is defined as:

$$
Q=\int_{t_{0}}^{t_{\mathrm{f}}} \frac{d t}{C_{\mathrm{t}}}
$$

$C_{\mathrm{t}}$ is dependent on alloy and temperature [29]. If a constant cooling rate is employed $Q$ is proportional to quenching duration and due to the linear relationship between quenching duration and cooling rate $\beta, Q$ is also 350 linearly proportional to $1 / \beta$.

Next we replace $C_{\mathrm{AQ}}$ from Eq. (1) with the enthalpy change during cooling to room temperature $\left|\Delta H_{\mathrm{RT}}\right|$. The value $C_{\min (\mathrm{T})}$ is replaced by the saturation level of enthalpy change at room temperature $\left|\Delta H_{\mathrm{RT}}\right|$ sat , which is reached in cases where cooling is slower than the LCCR. $C_{\max (\mathrm{T})}$ is replaced by the minimum change in enthalpy, which is obviously zero as far as cooling is performed overcritically fast. As $\beta$ is defined to be positive in this work the term in curved brackets becomes a positive sign as well. Rearranging the terms gives the fitting model: 


$$
\left|\Delta H_{\mathrm{RT}}\right|=\left|\Delta H_{\mathrm{RT}_{\text {sat }}}\right|-\left|\Delta H_{\mathrm{RT}_{\text {sat }}}\right|\left[\frac{\left(\frac{k_{\mathrm{M}}}{\beta}\right)^{n}}{\eta_{i}}+1\right]^{-\eta_{\mathrm{i}}}
$$

Herein, $k_{\mathrm{M}}$ is a parameter comprising $k_{1}$ and $C_{\mathrm{t}}$, i.e. it is alloy dependent. Thus to apply this model, we need to either fit or otherwise obtain $k_{\mathrm{M}}, n$ and $\eta_{\mathrm{i}}$. It has been shown $[33,35,36]$ that if nucleation is completed early on in the reaction $n$ should be 1.5. This would apply for heterogeneous nucleation e.g. at dispersoids or coarse intermetallic phases when the number of such sites is limited [19,37]. However, those phases are not present in 360 the pure binary alloys investigated in this paper, and hence, $n$ should be 2.5 , which is valid for continuous nucleation during the course of the reaction [19,37]. The parameter $\eta_{\mathrm{i}}$ is the impingement factor and its values found in literature typically range between about 1 and 2.2 when a single process occurs [19,32,33]. However, in the present case clearly multiple processes in a wide range of temperatures are involved, and we will here fit $\eta_{\mathrm{i}}$. Therefore, the values shown in Table 2 were calculated with the adapted fitting function and resultant fitting curves are shown in Fig. 5. The fit is excellent.

Table 2. Results from fitting measured DSC data to equation (3).

\begin{tabular}{c|cccc} 
& $\left|\Delta H_{\mathrm{RT}_{\mathrm{sat}}}\right|$ & $k \mathrm{M}$ & $\eta_{\mathrm{i}}$ & $n$ \\
\hline $\mathrm{Al}-0.26 \mathrm{Si}$ & $4.1 \mathrm{~J} / \mathrm{g}$ & $0.002 \mathrm{~K} / \mathrm{s}$ & 0.315 & 2.5 \\
$\mathrm{Al}-0.72 \mathrm{Si}$ & $11.3 \mathrm{~J} / \mathrm{g}$ & $0.053 \mathrm{~K} / \mathrm{s}$ & 0.164 & 2.5
\end{tabular}

Saturation value $\left|\Delta H_{\mathrm{RT}_{\mathrm{sat}}}\right|$ should be proportional to the Si content. Due to the limited DSC data at very low cooling rates for Al-0.26Si, $\left|\Delta H_{\mathrm{RT}_{\mathrm{sat}}}\right|$ for this alloy was estimated from value $\mid \Delta H_{\mathrm{RT}} \mathrm{sat}_{\text {sat }}=11.3 \mathrm{~J} / \mathrm{g}$ for Al- $0.72 \mathrm{Si}$ using the Si content proportion of both alloys. The enthalpy change of precipitation per mole Si from the Al-rich 370 matrix was experimentally studied in $[15,38]$ and was derived to be about $54 \mathrm{~kJ} \mathrm{~mol}^{-1}$. Taking this value into account, theoretically $\left|\Delta H_{\mathrm{RT}_{\text {sat }}}\right| \approx 13.2 \mathrm{~J} / \mathrm{g}$ for Al-0.72Si and $\mid \Delta H_{\mathrm{RT}}$ sat $\mid \approx 4.8 \mathrm{~J} / \mathrm{g}$ for Al-0.26Si result, respectively. Therefore, within experimental error the theoretical values agree well with the data presented in this work. Accuracy of the literature values is mainly determined by the value of enthalpy change of precipitation per mole $\mathrm{Si}$. Interfacial energies of precipitates formed may influence the results. Furthermore, small deviations can also be ascribed to the limited accuracy of DSC data (e.g. peak area determination) and to assumptions made in the adapted quench factor model.

As the enthalpy change is in direct proportion to the mass and volume fraction of precipitated particles $[18,19]$, the following equation can be applied to calculate the solute content at arbitrary temperatures $T_{\mathrm{c}}$ :

$$
\text { solute content }_{T_{\mathrm{c}}}=\left(c_{\mathrm{el}_{\text {total }}}-c_{\mathrm{el}_{\mathrm{sol}(\mathrm{RT})}}\right) \cdot\left(1-\frac{\left|\Delta H_{T_{\mathrm{c}}}(\beta)\right|}{\left|\Delta H_{\mathrm{RT}_{\mathrm{sat}}}\right|}\right)+c_{\mathrm{el}_{\mathrm{sol}(\mathrm{RT})}}
$$

Parameter $c_{\mathrm{el}_{\text {total }}}$ corresponds to the overall content of a specific alloying element in the material, while the soluble 380 content of this element at RT is taken into account with value $c_{\mathrm{e}_{\mathrm{sol}}(\mathrm{RT})} . \Delta H_{\mathrm{RT}}$ sat again is the saturation level of 
enthalpy change after cooling to room temperature. Value $\Delta H_{T_{\mathrm{c}}}(\beta)$ represents the enthalpy change at temperature $T_{\mathrm{c}}$ to which the alloy has already been cooled with cooling rate $\beta . \Delta H_{T_{\mathrm{c}}}(\beta)$ can thus be directly derived from integration of DSC curves taking the solution annealing temperature $T_{\text {an }}$ as upper bound of integration:

$$
\Delta H_{T_{\mathrm{c}}}(\beta)=\int_{T_{\mathrm{c}}}^{T_{\mathrm{an}}} c_{\mathrm{p}}(\beta) \mathrm{d} T
$$

While the maximum solubility of $\mathrm{Si}$ in the Al-rich matrix occurs at $577{ }^{\circ} \mathrm{C}$ with about 1.65 ma.\%, solubility decreases to about $0.05 \mathrm{ma} \%$ at $250{ }^{\circ} \mathrm{C}$ [16,39] and drops far below that value with further decrease of temperature [40]. Soluble amount of $\mathrm{Si}$ at $\mathrm{RT} c \mathrm{Si}_{\mathrm{sol}(\mathrm{RT})}$ therefore is negligible and equation (4) simplifies to

$$
\text { solute content }_{T_{\mathrm{c}}}=c_{\mathrm{Si}_{\text {total }}} \cdot\left(1-\frac{\left|\Delta H_{T_{\mathrm{c}}}(\beta)\right|}{\left|\Delta H_{\mathrm{RT}_{\mathrm{sat}}}\right|}\right)
$$

Solute mass fraction of Si reaches a maximum if the alloy is overcritically cooled to RT. No precipitation reactions occur $\left(\Delta H_{\mathrm{RT}_{\mathrm{oc}}}=0\right)$ in that case and the complete solid solution is retained. When saturation level $\left|\Delta H_{\mathrm{RT}_{\mathrm{sat}}}\right|$ is reached, all alloying elements should be precipitated leaving a negligible amount of Si in solid 390 solution.

As only the diamond cubic Si-rich phase is assumed to be precipitated from solid solution the precipitated $\mathrm{Si}$ mass fraction (precipitated ma.\% = overall ma.\% - solute ma.\%) can directly be converted into volume fraction of Si particles considering the densities of $\mathrm{Al}$ and $\mathrm{Si}$. The precipitated volume fraction in dependence of cooling rate and temperature can also be calculated with the presented model if the maximum possible precipitated volume fraction $\Phi_{\mathrm{Si}_{\max }}$ is evaluated first:

$$
\text { precipitated volume fraction }_{T_{\mathrm{c}}}=\Phi_{\mathrm{Si}_{\max }} \cdot \frac{\left|\Delta H_{T_{\mathrm{c}}}(\beta)\right|}{\left|\Delta H_{\mathrm{RT}_{\mathrm{sat}}}\right|}
$$

The binary Al-Si alloy with a Si content of 0.72 ma.\% was considered for the calculation exclusively. The computed solute mass fraction of Si (bold line) and the precipitated volume fraction of Si (thin line) after cooling to RT is shown in Fig. 6 in dependence of cooling rate. 


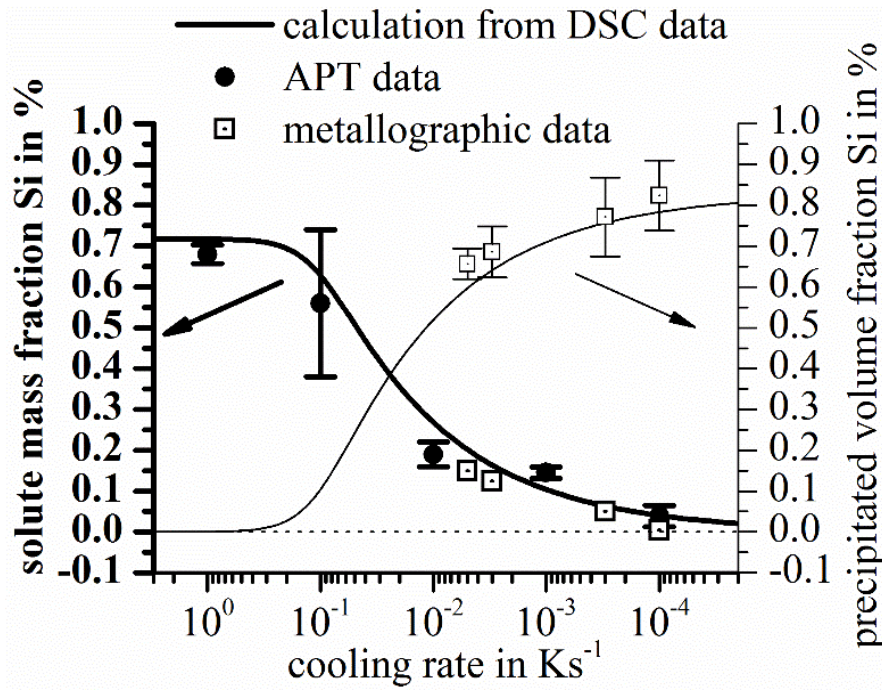

400 Fig. 6. Calculated solute mass fraction of $\mathrm{Si}$ (bold line) and calculated precipitated volume fraction (thin line) for Al $0.72 \mathrm{Si}$ after cooling to room temperature in comparison to APT data and results from metallographic analysis.

As the uncertainty of enthalpy values from DSC experiments are estimated to be up to $10 \%$ (resulting from peakarea determination), the calculated solute mass fraction needs to be verified. For this, five different cooling conditions were analysed by APT. Measured data are plotted in Fig. 6 for comparison with the calculated results. Standard deviations of three runs are represented by error bars. APT data after overcritical cooling with $1 \mathrm{~K} / \mathrm{s}$ $(0.680 \pm 0.023 \mathrm{ma} . \%)$ is in good agreement with the calculated solute mass fraction. It was assumed that no precipitation reactions occur in the time between quenching and APT measurements as formation of precipitates at RT is not reported in literature. Possible natural ageing processes [41,42], which would theoretically reduce the Si content in solid solution, are not considered in the measured composition. Measured values after cooling 410 with all rates also match the calculated data well. As presumed, solute mass fraction of Si decreases with decreasing cooling rate. The value determined by APT after cooling with $0.0001 \mathrm{~K} / \mathrm{s}(0.039 \pm 0.026$ ma.\%) matches the calculated solute mass fraction and indicates that not all Si has been precipitated in that condition. Fig. 6 also shows the precipitated volume fraction of Si obtained from metallographic analyses in comparison to computed data. For a better comparison with APT data, the mean values of solute mass fraction Si were calculated from these results and are also given in Fig. 6. Evaluated data from metallographic analyses is in accordance to the modelled data as well. The relatively large error bars for very slow cooling conditions can be explained by the distribution of precipitates. Slow cooling rates lead to an increasingly uneven distribution of precipitated particles, which results in higher scattering of analysed volume fractions in different metallographic images. Still, the executed experiments support the data obtained from the adapted model used for the calculation of solute 420 content.

\subsection{Characterisation of quench-induced precipitates}

It was demonstrated that during cooling in the DSC different reaction peaks correspond to the formation of different types of precipitates $[18,28]$. Coarse (dimensions some $\mu \mathrm{m}$ ) incoherent equilibrium phases are 
precipitated at high temperatures, while (partially) coherent precursor phases (length some $100 \mathrm{~nm}$ ) precipitate at lower temperatures for age-hardenable aluminium alloys. However, no precipitation sequence is known for binary Al-Si alloys. Nevertheless, at least two exothermic reactions during cooling were detected for alloy Al0.72Si (Fig. 2a). To gain additional information on the precipitated particles, metallographic studies after linear cooling from solution annealing to RT were performed on this alloy. LOM and SEM images for different cooling rates are shown in Fig. 7.
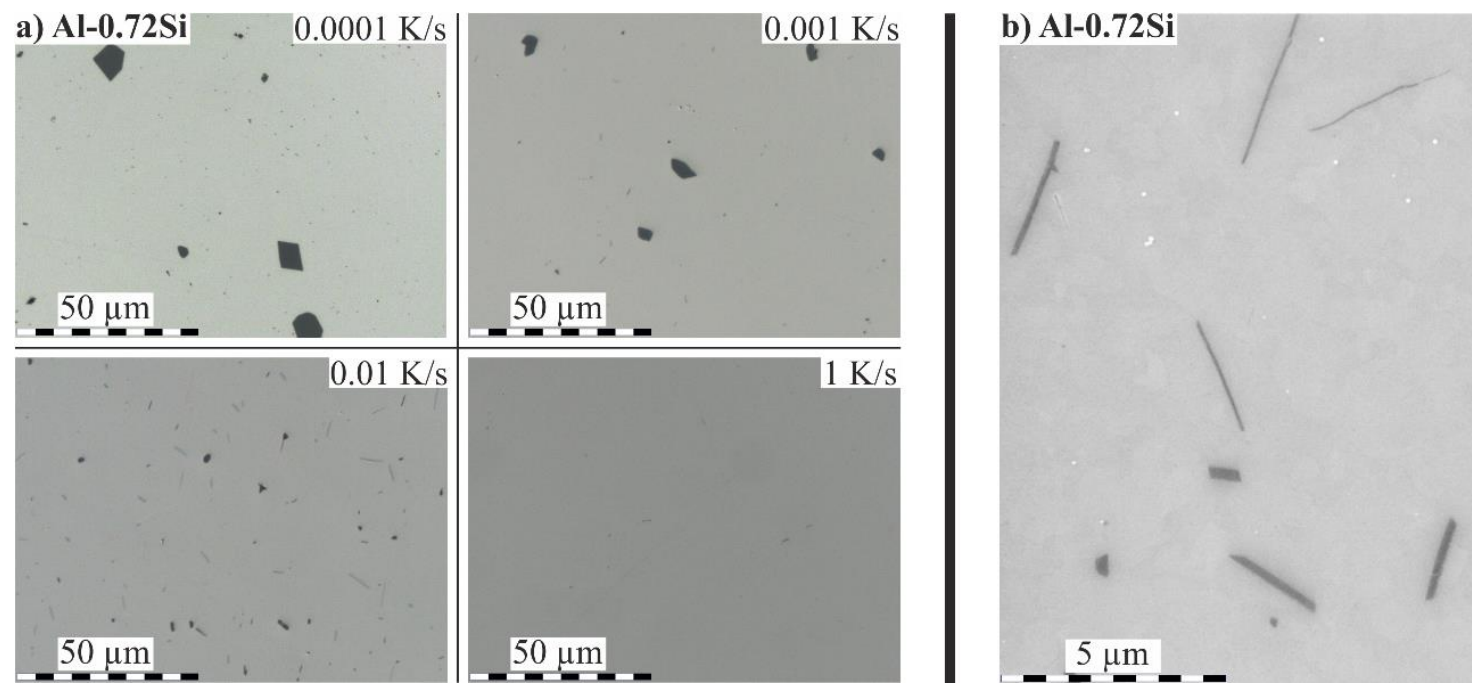

Fig. 7. LOM images of Al-0.72Si after cooling with different rates (a) and SEM image after cooling with $0.01 \mathrm{~K} / \mathrm{s}$ (b) from solution annealing to $\mathrm{RT}$.

DSC results indicated that a cooling rate of $1 \mathrm{~K} / \mathrm{s}$ is overcritically fast for Al-0.72Si. After cooling with this rate no secondary precipitates were traceable with LOM and nanosized precipitates were also not detected via APT, which supports the calorimetric findings. However, it cannot be fully excluded that small precipitates untraceable with LOM form at this cooling rate as APT measurements would only reveal such particles in case of a dense spatial distribution. At slower cooling rates precipitates were observed, of which most are precipitated inside aluminium solid solution grains. Few particles on grain boundaries could be detected as well. For a cooling rate of $0.01 \mathrm{~K} / \mathrm{s}$ at least two overlapping reaction peaks were detected by DSC (Fig. 2a). After cooling with this rate 440 coarse precipitates with different morphologies were found. On the one hand rods or platelets with lengths of some $\mu \mathrm{m}$ and high aspect ratios have formed. Besides, irregular-shaped polygonal particles with low aspect ratios and few $\mu \mathrm{m}$ in size are precipitated during cooling with this rate. A more detailed view on both precipitate morphologies provides the SEM image in Fig. 7b. With a further decrease of cooling rate, the amount of rod-/platelet-shaped particles is reduced and polygonal precipitates gain in size. At a cooling rate of $0.0001 \mathrm{~K} / \mathrm{s}$ very coarse polygonal particles (about $10 \mu \mathrm{m}$ ) are precipitated, while no rod-/platelet-shaped particles are visible anymore in LOM images.

It is well established in the literature that all precipitates in binary $\mathrm{Al}-\mathrm{Si}$ alloys are diamond cubic $\mathrm{Si}$-rich phase [15]. Our XRD experiments after cooling with $0.001 \mathrm{~K} / \mathrm{s}$ and $0.01 \mathrm{~K} / \mathrm{s}$ confirmed the presence of only the fcc Alrich phase and the diamond cubic Si-rich phase. Interestingly, overlapping DSC peaks ( $a_{1}$ and $a_{2}$ ) observed during 
450 heating of the water quenched condition (Fig. 3) indicate that the formation of precipitates with different shapes and sizes is not restricted to the cooling process. Precipitates of various shape were also found in other work after different ageing treatments $[15,43-45]$.

When the microstructural results are compared to the corresponding DSC cooling curves it can be assumed that the precipitation of polygonal particles takes place at high temperatures. Rod-/platelet-shaped precipitates on the other hand seem to be formed at lower temperatures. As the precipitation of particles with different morphologies seem to correspond to the reaction peaks measured by DSC a more detailed microstructural analysis was carried out to study the development of precipitate formation by a step quenching procedure introduced in [18]. The investigated samples were cooled with $0.001 \mathrm{~K} / \mathrm{s}$ and $0.01 \mathrm{~K} / \mathrm{s}$ to specific temperatures before they were overcritically cooled to maintain the precipitation state of interest.

460 The microstructure development of Al-0.72Si during cooling with $0.001 \mathrm{~K} / \mathrm{s}$ obtained from light microscopy is shown in Fig. 8a. No precipitates are visible at $490{ }^{\circ} \mathrm{C}$, which coincides with the DSC curve for this cooling rate as no reaction was detected at this temperature. According to Fig. 2a, the intensity maximum of the high temperature reaction peak is reached at $440{ }^{\circ} \mathrm{C}$. Coarse polygonal particles with low aspect ratios have already been formed at this temperature. With a further decrease of temperature the precipitates grow and the volume fraction increases. After cooling to room temperature a few rod-/platelet-shaped precipitates were detected. This indicates that the low temperature reaction is also present to a certain extent at this cooling rate and supports that these particles are formed at lower temperatures.

During cooling with $0.01 \mathrm{~K} / \mathrm{s}$ the maximum amount of heat is released by low temperature reactions. However, high temperature reactions are not fully suppressed when the alloy is cooled with this rate. At a temperature of $470435{ }^{\circ} \mathrm{C}$ only polygonal-shaped precipitates with much smaller dimensions compared to the slower cooling condition can be perceived, which correspond to high temperature reactions taking place in this temperature region (Fig. 2a). When a temperature of $395{ }^{\circ} \mathrm{C}$ is reached (low temperature reaction peak maximum) these particles have grown and first rods/platelets appear. With further decrease of temperature the polygonal-shaped particles seem to retain their form and size. This again supports the proposition that these particles form only at high temperatures. On the contrary, amount and size of rod-/platelet-shaped particles increases after passing the intensity maximum of the low temperature reactions. 


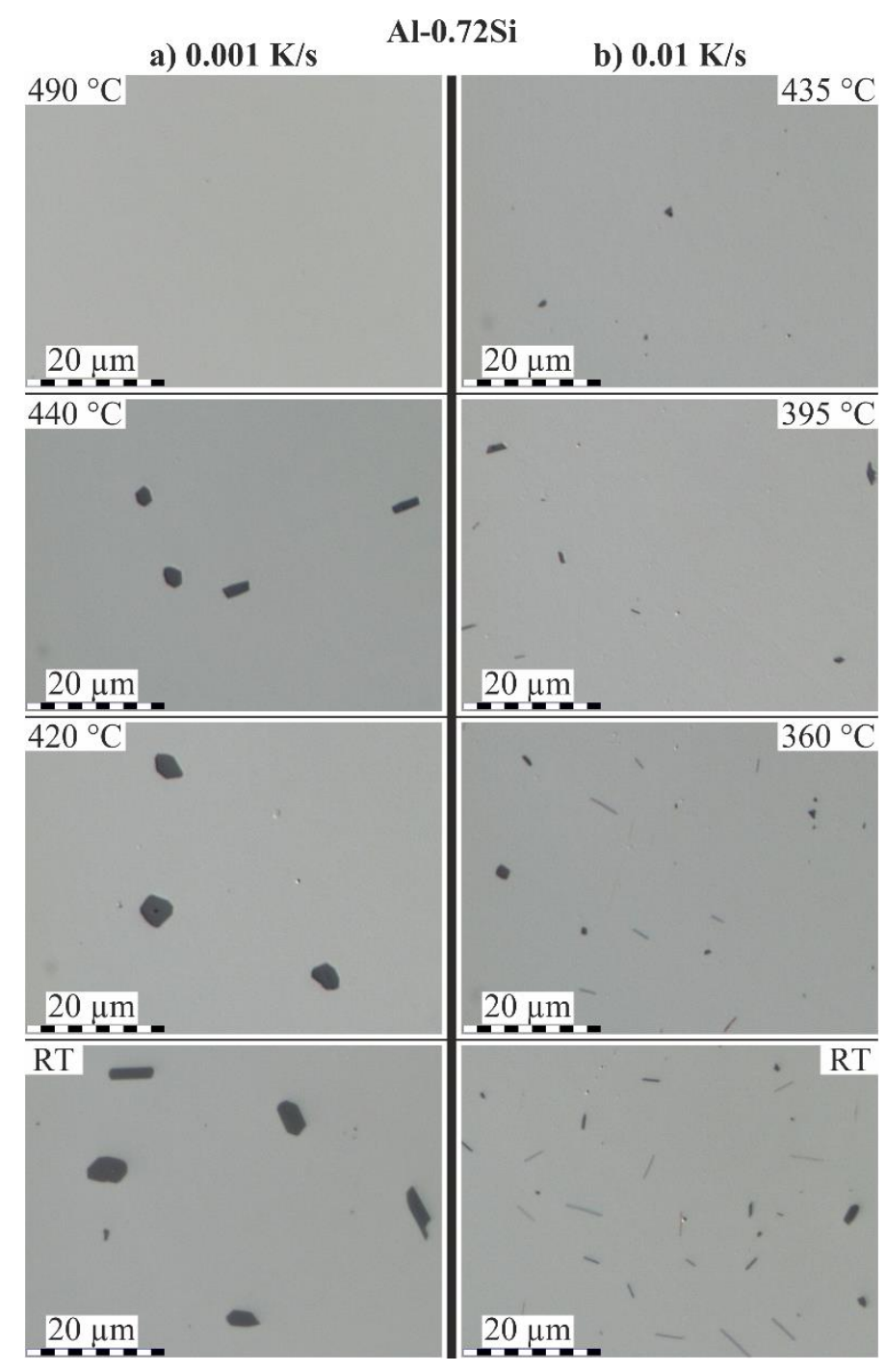

Fig. 8. LOM images of Al-0.72Si after cooling with $0.001 \mathrm{~K} / \mathrm{s}$ (a) and $0.01 \mathrm{~K} / \mathrm{s}$ (b) from solution annealing to specific temperatures followed by overcritical cooling.

480 The knowledge that precipitate morphologies are dependent on the growth temperature of particles provides an explanation for their varying shape [46]. With respect to classical nucleation theory, the driving force for solidphase transitions such as precipitation reactions can be ascribed to three major factors. The change in the Gibbs free energy $\Delta G$ when a nucleus forms can therefore be written as:

$$
\Delta G=-\Delta G_{\mathrm{vol}}+\Delta G_{\mathrm{sur}}+\Delta G_{\mathrm{str}}
$$

While $\Delta G_{\mathrm{vol}}$ is related to the energy gain due to creation of new volume, $\Delta G_{\text {sur }}$ (surface energy) and $\Delta G_{\text {str }}$ (strain energy) represent inhibitory energies for phase transition. If nucleation is mainly arrested by creation of new interfaces, globular/polygonal nuclei and particles will form because of their small surface to volume fraction. This seems to be the case at high temperatures. Plate- or rod-shaped particles are precipitated if the strain term is the dominating factor. This can be explained with lower strain energy of particles with this shape. Vacancies in binary fcc alloys also play an important role in nucleation [44] as they increase the diffusion rate of solute atoms 490 at moderate temperatures and thus increase the growth rate of solute clusters. Furthermore, vacancies may become part of nuclei and can reduce the barrier to precipitation. 


\subsection{Thermo-mechanical analyses}

Flow characteristics of $\mathrm{Al}-0.72 \mathrm{Si}$ during the cooling process were examined by TMA dependent on cooling condition and temperature. In correlation with data from DSC cooling experiments and microstructural analyses information on the effect of Si solutes and quench-induced Si precipitates on mechanical properties can be discussed. Three cooling rates $(1 \mathrm{~K} / \mathrm{s}, 0.01 \mathrm{~K} / \mathrm{s}, 0.001 \mathrm{~K} / \mathrm{s})$, showing very different precipitation behaviour, were studied. Compression tests after cooling with these rates were carried out at four different temperatures $\left(500{ }^{\circ} \mathrm{C}\right.$, $\left.400{ }^{\circ} \mathrm{C}, 300{ }^{\circ} \mathrm{C}, 30{ }^{\circ} \mathrm{C}\right)$. The results of these tests are given in Fig. 9.


500 Fig. 9. Stress-strain curves of alloy Al-0.72Si from compression tests with a strain rate of $0.1 \mathrm{~s}^{-1}$ at different temperatures $T_{\mathrm{c}}$ after cooling with different rates from solution annealing.

Identical flow curves were recorded at a temperature of $T_{\mathrm{c}}=500{ }^{\circ} \mathrm{C}$ for all cooling rates. This can be explained with the absence of precipitation reactions in this temperature range (Fig. 2a), meaning that all Si atoms remain in solution for all states. At $T_{\mathrm{c}}=400{ }^{\circ} \mathrm{C}$ a decrease in strength was detected with decreasing cooling rate, which clearly results from a loss of solute $\mathrm{Si}$ atoms. Even greater differences in the flow stress can be observed at a temperature of $T_{\mathrm{c}}=300{ }^{\circ} \mathrm{C}$ as further precipitation reactions occur in this temperature region. At both temperatures the flow stress at the initial stage of plastic deformation and at higher strains is affected nearly equally. 
A main difference between cooling rates $0.01 \mathrm{~K} / \mathrm{s}$ and $0.001 \mathrm{~K} / \mathrm{s}$ is the morphology of the main precipitated 510 particles as was shown in Fig. 8. Interestingly, strain hardening at high temperatures does not seem to be influenced by the quench-induced precipitates and similar work hardening rates were observed in all conditions. Work hardening is generally weak due to extensive dynamic recovery. On the other hand, work hardening rates at low temperatures seem to be affected by quench-induced precipitates formed during slow cooling. At $T_{\mathrm{c}}=30^{\circ} \mathrm{C}$ overcritically cooled samples again show the highest yield strength, implying that precipitated particles are too coarse to contribute to strength at the initial stage of plastic deformation. The yield strength hence seems to be controlled by the solute Si content. However, higher strain hardening rates up to a total strain of about 0.03 were observed for samples containing precipitates. With further increase of strain work hardening rates drop below that of precipitate-free samples. Complete solid solution thus showed a more linear hardening, while a parabolic hardening was observed for states containing quench-induced precipitates and lower solute content.

520 Similar observations were recently made in Al-Mn alloys containing different dispersoid densities [47,48]. A higher amount of non-shearable particles led to an increased work hardening at the initial plastic deformation, but the effect was opposite at higher strains. The more parabolic hardening, compared to a lower density of dispersoids, resulted in a crossover in the stress-strain curves similar to the results presented here. The reason for increased work hardening rates at the initial plastic deformation has been attributed to the generation of geometrically necessary dislocations (GNDs), on which Ashby [49] proposed a basic theory. It was assumed that the local dislocation density saturates at a certain amount of strain and volume fractions containing GNDs no longer contribute to further work hardening. Decreased hardening rates at higher strains therefore seems to be related to the storage and dynamic recovery of the GNDs during deformation at room temperature [48]. Although no detailed study regarding precipitate-matrix interfaces have been performed so far, most quench-induced 530 particles in Al-Si should be incoherent with the matrix and hence non-shearable due to their sizes. Thus, work hardening characteristics of Al-Si with quench-induced precipitates might also be influenced by the generation of GNDs. A more refined discussion of this effect will require a comprehensive model that is able to consider work hardening, dynamic recovery, particle and solid solution strengthening concurrently, which is beyond the scope of the present paper.

\section{Summary}

In this work an approach to explore the effect of solutes and quench-induced precipitates on mechanical properties during cooling from solution annealing has been introduced on binary Al-Si alloys. Application of advanced DSC techniques for determination of precipitation enthalpies upon cooling from solution annealing (cooling rates between $2 \mathrm{~K} / \mathrm{s}$ and $0.0001 \mathrm{~K} / \mathrm{s}$ ) allows the determination of solid solution states based on an introduced physically-

540 based approach. Microstructural analyses by the use of light optical microscopy, scanning electron microscopy, atom probe and X-ray diffraction support the modelled solute states and it is found that quench-induced precipitates of different morphology form dependent on cooling rate. Form and size of quench-induced particles 
depend on the temperature range in which they are precipitated. Coarse irregular-shaped, polygonal precipitates are formed at high temperatures, while particles precipitated at lower temperatures seem to be rods or platelets. Thermomechanical analyses showed that the strength of binary Al-Si during the cooling process is significantly influenced by temperature and cooling rate as different microstructural changes occur. Quench-induced Si precipitates appear to have no contribution to yield strength of the alloy due to their sizes. Onset of plastic deformation is therefore mostly controlled by the present amount of Si solutes. While work hardening characteristics of Al-0.72Si at elevated temperatures also seem not to be influenced by precipitated particles, 550 increased strain hardening rates at the initial stage of plastic deformation are observed at low temperatures in samples with quench-induced precipitates. At higher strains work hardening rates are reduced. This results in a rather parabolic hardening compared to precipitate-free conditions, which show a more linear hardening.

The presented experimental approach can be used for a detailed study on the correlation between microstructural states of non-equilibrium alloy conditions and their mechanical behaviour in future work. With knowledge of microstructural changes upon cooling appropriate heat treatment parameters can be derived to control the microstructure and thereby produce well-defined material conditions. Comparison of these states by means of thermomechanical analyses will allow the investigation of strength contribution of solute $\mathrm{Si}$ and strengthening effects of quench-induced precipitates with different morphologies. Consequently, information on active strengthening mechanisms can be obtained to improve plasticity models.

\section{Acknowledgements}

The authors gratefully acknowledge funding of this work by Deutsche Forschungsgemeinschaft (MO974/4-1 and MI1731/1-1). Besides, part of this work was supported by a fellowship within the Postdoc-Program of the German Academic Exchange Service (DAAD) for Benjamin Milkereit.

\section{References}

[1] I.J. Polmear, Light alloys, 4th ed., Elsevier/Butterworth-Heinemann, Oxford, 2006.

[2] M. Reich, O. Kessler, Quenching Simulation of Aluminum Alloys Including Mechanical Properties of the Undercooled States, Matls Perf Charact 1 (2012) 104632. doi:10.1520/MPC104632.

[3] M. Goerdeler, G. Gottstein, A microstructural work hardening model based on three internal state variables, Mater Sci Eng A 309-310 (2001) 377-381. doi:10.1016/S0921-5093(00)01728-7.

570 [4] U.F. Kocks, H. Mecking, Physics and phenomenology of strain hardening: The FCC case, Prog Mater Sci 48 (2003) 171-273. doi:10.1016/S0079-6425(02)00003-8.

[5] E. Nes, Modelling of work hardening and stress saturation in FCC metals, Prog Mater Sci 41 (1998) 129193. doi:10.1016/S0079-6425(97)00032-7. 
[6] F. Roters, D. Raabe, G. Gottstein, Work hardening in heterogeneous alloys - a microstructural approach based on three internal state variables, Acta Mater 48 (2000) 4181-4189. doi:10.1016/S13596454(00)00289-5.

[7] G.V.S.S. Prasad, An Improved Dislocation Density Based Work Hardening Model for Al-alloys, PhD thesis, Aachen, 2007.

[8] V. Mohles, X. Li, C. Heering, G. Hirt, S. Bhaumik, G. Gottstein, Validation of an improved dislocation density based flow stress model for Al-alloys, Int J Mater Form 1 (2008) 77-80. doi:10.1007/s12289-0080040-1.

[9] M. Reich, O. Kessler, Mechanical properties of undercooled aluminium alloys and their implementation in quenching simulation, Mater Sci Tech 28 (2012) 769-772. doi:10.1179/1743284711Y.0000000085.

[10] Ø. Ryen, O. Nijs, E. Sjölander, B. Holmedal, H.-E. Ekström, E. Nes, Strengthening mechanisms in solid solution aluminum alloys, Metall Mat Trans A Phys Metall Mat Sci 37 (2006) 1999-2006. doi:10.1007/s11661-006-0142-7.

[11] B. Rønning, K. Nord-Varhaug, T. Furu, E. Nes, Effect of chemical composition and microstructure on the flow stress during hot deformation of aluminum alloys, Mater Sci Forum 331-337 (2000) 571-576. doi:10.4028/www.scientific.net/MSF.331-337.571.

590 [12] Ø. Ryen, H.I. Laukli, B. Holmedal, E. Nes, Large strain work hardening of aluminum alloys and the effect of Mg in solid solution, Metall Mat Trans A Phys Metall Mat Sci 37 (2006) 2007-2013. doi:10.1007/s11661-006-0143-6.

[13] Q. Zhao, B. Holmedal, The effect of silicon on the strengthening and work hardening of aluminum at room temperature, Mater Sci Eng A 563 (2013) 147-151. doi:10.1016/j.msea.2012.11.062.

[14] R. Akeret, Deformation of aluminum and aluminum alloys at different temperatures, Z Metallk 61 (1970) 3-10.

[15] M.J. Starink, A.-M. Zahra, Kinetics of isothermal and non-isothermal precipitation in an Al - 6 at.\% Si alloy, Philos Mag A 77 (1998) 187-199. doi:10.1080/01418619808214237.

[16] M. Hansen, K. Anderko, Constitution of binary alloys, 2nd ed., McGraw-Hill, New York, 1958. 600 [17] J.L. Murray, A.J. McAlister, The Al-Si (Aluminum-Silicon) system, Bull Alloy Phase Diagr 5 (1984) 74-84. doi:10.1007/BF02868729.

[18] B. Milkereit, N. Wanderka, C. Schick, O. Kessler, Continuous cooling precipitation diagrams of Al-MgSi alloys, Mater Sci Eng A 550 (2012) 87-96. doi:10.1016/j.msea.2012.04.033.

[19] M.J. Starink, Analysis of aluminium based alloys by calorimetry: Quantitative analysis of reactions and reaction kinetics, Int Mater Rev 49 (2004) 191-226. doi:10.1179/095066004225010532.

[20] P. Schumacher, M. Reich, V. Mohles, S. Pogatscher, P.J. Uggowitzer, B. Milkereit, Correlation between supersaturation of solid solution and mechanical behaviour of two binary Al-Si-alloys, Mater Sci Forum 794-796 (2014) 508-514. doi:10.4028/www.scientific.net/MSF.794-796.508. 
[21] B. Milkereit, J. Osten, C. Schick, O. Kessler, Continuous Heating Dissolution Diagrams of Aluminum 610 Alloys, in: H. Weiland, A.D. Rollett, W.A. Cassada (Eds.), ICAA13: 13th International Conference on Aluminum Alloys, John Wiley \& Sons, Inc., Hoboken, NJ, 2012, pp. 1095-1100. doi:10.1002/9781118495292.ch164.

[22] B. Milkereit, O. Kessler, C. Schick, Recording of continuous cooling precipitation diagrams of aluminium alloys, Thermochim Acta 492 (2009) 73-78. doi:10.1016/j.tca.2009.01.027.

[23] B. Milkereit, M. Beck, M. Reich, O. Kessler, C. Schick, Precipitation kinetics of an aluminium alloy during Newtonian cooling simulated in a differential scanning calorimeter, Thermochim Acta 522 (2011) 86-95. doi:10.1016/j.tca.2011.02.034.

[24] D. Zohrabyan, B. Milkereit, O. Kessler, C. Schick, Precipitation enthalpy during cooling of aluminum alloys obtained from calorimetric reheating experiments, Thermochim Acta 529 (2012) 51-58. doi:10.1016/j.tca.2011.11.024.

[25] M. Reich, B. Milkereit, M. Krawutschke, J. Kalich, C. Schick, O. Kessler, Advanced Dilatometry and Calorimetry for the Validation of Materials Mechanical and Transformation Models, in: M. Li, C.

Campbell, K. Thornton, E. Holm, P. Gumbsch (Eds.), 2nd World Congress on Integrated Computational Materials Engineering, John Wiley \& Sons, Inc., Hoboken, NJ, 2013, pp. 177-182. doi:10.1002/9781118767061.ch28.

[26] D. Zohrabyan, B. Milkereit, C. Schick, O. Kessler, Continuous Cooling Precipitation Diagram of a High Alloyed Al-Zn-Mg-Cu alloy 7049A, T Nonferr Metal Soc (2013) accepted manuscript.

[27] B. Milkereit, L. Giersberg, O. Kessler, C. Schick, Isothermal time-temperature-precipitation diagram for an aluminum alloy 6005A by in situ DSC experiments, Mater 7 (2014) 2631-2649. 630 doi:10.3390/ma7042631.

[28] Y. Zhang, B. Milkereit, O. Kessler, C. Schick, P.A. Rometsch, Development of continuous cooling precipitation diagrams for aluminium alloys AA7150 and AA7020, J Alloys Compd 584 (2014) 581-589. doi:10.1016/j.jallcom.2013.09.014.

[29] P.A. Rometsch, M.J. Starink, P.J. Gregson, Improvements in quench factor modelling, Mater Sci Eng A 339 (2003) 255-264. doi:10.1016/S0921-5093(02)00110-7.

[30] H. Oettel, H. Schumann, Metallografie, 14th ed., Wiley-VCH, Weinheim, 2005.

[31] M.K. Miller, Atom probe field ion microscopy, Clarendon Press; Oxford University Press, Oxford, New York, 1996.

[32] M.J. Starink, A.-M. Zahra, An analysis method for nucleation and growth controlled reactions at 640 constant heating rate, Thermochim Acta 292 (1997) 159-168. doi:10.1016/S0040-6031(96)03135-8.

[33] M.J. Starink, On the meaning of the impingement parameter in kinetic equations for nucleation and growth reactions, J Mater Sci 36 (2001) 4433-4441. doi:10.1023/A:1017974517877. 
[34] M.J. Starink, Kinetic equations for diffusion-controlled precipitation reactions, J Mater Sci 32 (1997) 4061-4070.

[35] M.J. Starink, A new model for diffusion-controlled precipitation reactions using the extended volume concept, Thermochimica Acta 596 (2014) 109-119. doi:10.1016/j.tca.2014.09.016.

[36] J.W. Christian, The Theory of Transformations in Metals and Alloys, Part 1, 2nd ed., Pergamon Press, Oxford, 1975.

[37] F.L. Cumbrera, F. Sánchez-Bajo, The use of the JMAYK kinetic equation for the analysis of solid-state 650 reactions: critical considerations and recent interpretations, Thermochim Acta 266 (1995) 315-330. doi:10.1016/0040-6031(95)02554-5.

[38] M. van Rooyen, E.J. Mittemeijer, Precipitation of silicon in aluminum-silicon: a calorimetric analysis of liquid-quenched and solid-quenched alloys, Metall Trans A 20 A (1989) 1207-1214. doi:10.1007/BF02647402.

[39] L.F. Mondolfo, Aluminum alloys, Butterworths, London, Boston, 1976.

[40] K.S. Lee, Direct observations of Al-Si junction interface, Korean J Electron Microsc 8 (1978) 77-79.

[41] K. Nakagawa, T. Kanadani, L. Anthony, H. Hashimoto, Microstructural changes at the initial stage of precipitation in an aluminum-silicon alloy, Mater Trans 46 (2005) 779-783. doi:10.2320/matertrans.46.779.

[42] M.J. Starink, L.F. Cao, P.A. Rometsch, A model for the thermodynamics of and strengthening due to 660

[43] H.S. Rosenbaum, D. Turnbull, Metallographic investigation of precipitation of silicon from aluminum, Acta Metall 7 (1959) 664-674. doi:10.1016/0001-6160(59)90143-9.

[44] E. Hornbogen, A.K. Mukhopadhyay, Starke Jr. E. A., Nucleation of the diamond phase in aluminiumsolid solutions, J Mater Sci 28 (1993) 3670-3674. doi:10.1007/BF01159852.

[45] F. Lasagni, B. Mingler, M. Dumont, H.P. Degischer, Precipitation kinetics of Si in aluminium alloys, Mater Sci Eng A 480 (2008) 383-391. doi:10.1016/j.msea.2007.07.008.

[46] D.A. Porter, K.E. Easterling, Phase transformations in metals and alloys, 2nd ed., Nelson Thornes Ltd, Cheltenham, 2001.

[47] Q. Zhao, B. Holmedal, Y. Li, Influence of dispersoids on microstructure evolution and work hardening 670 of aluminium alloys during tension and cold rolling, Philos Mag 93 (2013) 2995-3011. doi:10.1080/14786435.2013.794315.

[48] Q. Zhao, B. Holmedal, Modelling work hardening of aluminium alloys containing dispersoids, Philos Mag 93 (2013) 3142-3153. doi:10.1080/14786435.2013.805271.

[49] M.F. Ashby, Deformation of plastically non-homogeneous materials, Philos Mag 21 (1970) 399-424. doi:10.1080/14786437008238426. 


\section{List of figure captions}

Fig. 1. Temperature-time profile for indirect determination of specific precipitation heat values during cooling with very slow rates by a DSC reheating scan.

Fig. 2. DSC cooling curves of alloys Al-0.72Si (a) and Al-0.26Si (b) after solution annealing in a cooling rate 680 range from $0.001 \mathrm{~K} / \mathrm{s}$ to $2 \mathrm{~K} / \mathrm{s}$.

Fig. 3. DSC reheating curves (scan rate: $0.003 \mathrm{~K} / \mathrm{s}$ ) of alloy Al-0.72Si in different cooling conditions (cc)....10

Fig. 4. Change of enthalpy state during reheating (scan rate: $0.003 \mathrm{~K} / \mathrm{s}$ ) of Al-0.72Si in different cooling conditions (cc). .11

Fig. 5. Enthalpy change values $\left|\Delta H_{\mathrm{RT}}\right|$ upon precipitation in Al-Si alloys after cooling to room temperature obtained with direct DSC cooling experiments or DSC reheating experiments and fitting results with the model presented in Eq. (3). .12

Fig. 6. Calculated solute mass fraction of $\mathrm{Si}$ (bold line) and calculated precipitated volume fraction (thin line) for $\mathrm{Al}$ 0.72Si after cooling to room temperature in comparison to APT data and results from metallographic analysis.

690 Fig. 7. LOM images of Al-0.72Si after cooling with different rates (a) and SEM image after cooling with $0.01 \mathrm{~K} / \mathrm{s}(\mathrm{b})$ from solution annealing to RT. 16

Fig. 8. LOM images of Al-0.72Si after cooling with $0.001 \mathrm{~K} / \mathrm{s}$ (a) and $0.01 \mathrm{~K} / \mathrm{s}$ (b) from solution annealing to specific temperatures followed by overcritical cooling. .18

Fig. 9. Stress-strain curves of alloy Al-0.72Si from compression tests with a strain rate of $0.1 \mathrm{~s}^{-1}$ at different temperatures $T_{\mathrm{c}}$ after cooling with different rates from solution annealing.

\section{List of table captions}

Table 1. Chemical compositions of investigated alloys obtained by optical emission spectroscopy (OES) analysis.

Table 2. Results from fitting measured DSC data to equation (3). 